\title{
DANTE AlighierI: A Monarquia Universal e A "Felicità MENTALE"
}

Gabriel Ferreira de Almeida Paizani ${ }^{45}$

Resumo: Dante Alighieri (1265-1321) nasceu numa Florença fragmentada e caracterizada pelo constante conflito entre facções políticas. Envolveu-se ativamente na vida política e, devido ao seu engajamento, foi exilado. Os conflitos entre o poder temporal e espiritual, especialmente entre Filipe IV e Bonifácio VIII, em conjunto com a passagem de Henrique VII pela Itália, criaram condições para a construção do tratado político De Monarchia (1312-1313). Dante Alighieri foi influenciado pela inserção do pensamento aristotélico no Ocidente e apropriou-se deste "novo" conjunto teórico para argumentar em favor da Monarquia Universal, no entanto, mesmo que nítida a importância dedicada à defesa do papel político do sujeito, sustentou também a virtude da nobreza intelectual, caracterizada pela contemplação filosófica.

Palavras-chave: Monarquia Universal; filosofia medieval; nobreza intelectual.

Para Dante Alighieri, a virtude suprema do homem não consiste em existir pura e simplesmente, mas antes receber as formas inteligíveis dos outros seres num intelecto possível. Esta é a perfeição que não convém a nenhum outro ser senão ao homem. A perfeição suprema da potência específica do homem reside na faculdade ou virtude da intelecção (1973, Mon., III, XVI). É assim que o florentino percebe a primeira finalidade do homem enquanto na vida terrena, atividade necessária para o alcance da beatitude terrestre, um meio para impetrar uma grandeza ainda maior, a beatitude eterna. Caminhos conjugados e apresentados no tratado político De Monarchia. O exercício intelectual não pode passar a ato, inteira e simultaneamente, se feito isoladamente: então, essa potência intelectual se atualiza somente por meio da pluralidade de seres corruptíveis - os homens. É por esta razão que o gênero humano existe. Para isto, os indivíduos que possuem todas as faculdades ordenadas para o alcance da felicidade necessitam de um guia, o Monarca Universal.

O artigo pretende oferecer um breve panorama das possíveis influências que permeiam o pensamento político-filosófico de Dante Alighieri, na tentativa de demonstrar como a figura do Monarca Universal construída no Monarchia esta relacionada ao homem nobre escolhido por Deus e destinado à contemplação filosófica.

1. Com recorrência, na história das idéias políticas medievais, teorizações mais concretas de uma instituição sócio-política surgem quando a sustentação efetiva dessas teorias se manifesta em declínio ou até mesmo na impossibilidade de serem aplicadas. O conceito de Império ganhou força quando já não passava de um ideal abstrato e com fraco fundamento prático na realidade, num momento em que as monarquias nacionais questionavam a preeminência da monarquia universal reivindicada pelo Sacro Império Romano Germânico (BARBOSA; SOUZA, 1997, p. 149). E é neste universo que Dante Alighieri está inserido. 
A partir do final do século XIII, Filipe IV encontra-se em guerra com Eduardo I da Inglaterra devido a questões político-econômicas e feudais. Para financiar esta guerra, ambos monarcas passaram a cobrar tributação da Igreja. Entre os clérigos de opinião contrária às exigências da coroa francesa, encontrava-se Bernardo Saisset, Bispo de Pamiers e partidário de Bonifácio VIII. Como represália às acusações, Saisset é detido e acusado de crime de lesa-majestade. Bonifácio enxergou nisto mais uma afronta ao seu poder e como resposta promulgou duas bulas: a Salvator mundi e Ausculta fili charissime, que acusaram Filipe de abuso de poder e gastos imoderados das rendas dos proventos das igrejas e catedrais do reino, assim como há um chamado para que o monarca se apresente, visando a salvação e preservação do reino francês.

Para contrapor os argumentos da Cúria Papal, Filipe IV possuía assessores e juristas burgueses, ${ }^{46}$ como Guilherme de Nogaret, os quais tinham como embasamento o direito romano, devido a sua precisão de conceitos e definições e por sua conseqüência lógica aplicável a todos os casos. Em conjunto com o pensamento político de Aristóteles, defendiam o conhecido princípio enunciado no Digesto - quod principi placuit, legis habet vigorem, ${ }^{47}$ apregoando que o rei devia ser o princeps no sentido jurídico-político da palavra, ou seja, a fonte e a origem de toda a lei. Em nome do bem-comum os juristas não admitiam que houvesse limites ao poder do rei, afinal o poder provinha diretamente de Deus e sem a intervenção da Igreja (BARBOSA; SOUZA, 1997, p. 153).

Inserido neste contexto de querela entre o poder temporal e espiritual, a partir de 1308 , com a eleição de Henrique VII, percebe-se que o imperador se sustentava na tradição universalista do título imperial e também nas pretensões já desenvolvidas pela dinastia Staufen. Assim, é possível que Henrique tenha recorrido a algumas construções teórico-jurídicas observáveis nos círculos gibelinos da Itália setentrional durante o século XIV. De acordo com Miethke (1993, p. 133-4), em 1310, o monarca marchou com um pequeno exército pela Itália onde era ansiosamente esperado, principalmente por quem esperava que interferisse nos conflitos entre os partidos opostos. Por mais que, a princípio, desejasse uma política de neutralidade, isto não foi possível, visto que sua própria força militar não era suficiente para deter as resistências que se apresentavam. A presença do imperador no norte da Itália só fez com que os numerosos conflitos se reavivassem em torno da disputa entre os guelfos e gibelinos. Em Milão, Henrique não consegue manter sua posição de pacificador frente aos dois partidos e intervém numa agitação local em 1311 ao defender o gibelino Mateo Visconti contra o guelfo e senhor da cidade, Guido della Torre. Assim, esta primeira tomada de posição gerou inevitavelmente outras; a missão de paz que Dante tanto havia esperado e descrito literariamente aos seus conterrâneos se converteu em uma réplica das campanhas bélicas de Frederico II no norte da Itália.

A Europa do século XIII há mais de cem anos conhecia intensa atividade econômica e intelectual,

46 Segmento social interessado na centralização do poder político nas mãos do monarca, visto que seus interesses econômicos são entravados pela nobreza feudal e pelo clero - grandes proprietários de terra. Cf. BARBOSA, João Morais; SOUZA, José Antônio de C. R. de. O Reino de Deus e o Reino dos Homens. As relações entre os poderes espiritual e temporal na Baixa Idade Média (da Reforma Gregoriana a João Quidort). Porto Alegre: EDIPUCRS, 1997. 
acelerado crescimento demográfico/territorial e desenvolvimento de novas formas sociais e políticas. E a Itália nesse momento era uma espécie de síntese européia, nela ocorriam de maneira muito acentuada os conflitos entre o Papado e um dos agentes do poder temporal-o Sacro Império Romano Germânico (FRANCO JR, 2000, p. 15-6).

Assim, em Florença a consolidação do poder laico não se deu sem conflitos, afinal, a nobreza reacionária queria assegurar seu antigo poder enquanto a burguesia ganhava em dinamismo e buscava maior influência política. Desde o início do século XIII, a divisão de posições entre dois grandes partidos nobres pelo controle da cidade era característica: os guelfos buscando apoio junto ao Papa e os gibelinos junto ao Imperador - lembrando que esta estrutura não era rígida, os dois partidos optavam politicamente pelo lado que lhe assegurasse maiores vantagens. Em 1293, com a Ordenação da Justiça, a cisão entre os nobres e o povo tornou-se definitiva: os membros das famílias nobres foram excluídos dos cargos públicos e a participação política passou a ser condicionada à inscrição em uma corporação. A partir dessa Ordenação e de anteriores reformas, nasceu uma nova divisão partidária seguida de uma guerra civil. Devido a conflitos entre duas famílias de Pistóia, Florença fortalece essa divisão: os guelfos se dividem em "brancos" e "negros", os primeiros tendiam a permanecer ao lado do Imperador e se aproximar da corrente gibelina. Dante pertencia à facção dos guelfos brancos, e no momento em que Carlos de Valois, aliado dos guelfos negros, intervém e derruba o governo de Florença, Dante é condenado à morte com outros florentinos e nunca mais retorna a sua cidade natal (DORÉ, 1997, p. 98-9).

Dante não era um teólogo, nem um monge mendicante como a maioria dos autores deste período, no entanto, recebeu das ordens religiosas de Florença, uma formação genuinamente escolástica. Partiu de bases explicitamente aristotélicas, mas diferentemente de seus predecessores, que seguiram a tendência da época sobre a ordem política particular baseando-se nos textos sobre a cidade-estado dos gregos, dotou o Império de um sólido fundamento teórico e demonstrou que o Império Romano constituiu uma necessidade, defendendo de forma inovadora o cargo e a função de Imperador como monarcha totius mundi (MIETHKE, 1993, p. 140).

O tratado De Monarchia (1312-3), seguindo o método escolástico, é dividido em três problemas: primeiro, se o cargo de imperador universal é necessário para o bem-estar e a boa ordem do mundo; segundo, se o povo romano exerceu o Império legitimamente; terceiro, se a auctoritas do domínio universal romano depende imediatamente de Deus ou do Papa. Dante desenvolve a idéia de que o fim do homem natural de nenhuma maneira depende da felicidade eterna, pois o primeiro fim é concebido como uma felicidade autônoma e independente da eterna. A unidade política é necessária e somente assim seria possível estabelecer a paz, objetivo buscado e necessário a todos, formando um ambiente para a criação de uma sociedade perfeita. Vale lembrar que a Monarquia defendida não se tratava de um regime político, mas antes um conceito de unidade figurado na universalidade. De acordo com Etienne Gilson (1965, p. 129): 
uma sociedade do gênero humano, verdadeiramente universal [...]. Dante considera a Igreja uma monarquia universal, mas cuja universalidade vem precisamente de sua espiritualidade. Tal como o concebe, o Império Romano, é, ao contrário, uma sociedade propriamente política, coextensiva à totalidade do gênero humano [...] Todos os homens são chamados a fazer parte dele sem distinção de raça, nem de religião. Um de seus argumentos contra a primazia temporal dos papas não reside no fato de que continentes inteiros recusam conhecer a sua autoridade espiritual? Devem, não obstante, reconhecer a autoridade temporal do imperador. Em outros termos, [...] nãa é necessário que um povo pertença à Igreja para que pertença ao Império. Não se trata mais de Igreja, nem de Cristandade, nem de Cidade de Deus: todos são chamados, todos são eleitos. A monarquia romana de Dante é a primeira fórmula moderna de uma sociedade temporal única, do gênero humano inteiro.

A Monarquia seria o princípio e não o fim, o começo de algo que deveria continuar. Dante cria um tratado sem possibilidades de ser aplicado naquele momento, buscando um passado italiano de predestinação num momento em que a fé e a lógica ainda não eram bem aceitos em conjunto, sustentando uma distinção mais precisa entre o poder temporal e espiritual, não implicando necessariamente numa oposição ou separação entre eles, tendo em vista o duplo fim do homem, o qual deve ser guiado pelo Imperador e pelo Papa.

No entanto, para entender um pouco dessa construção político-filosófica, somos remetidos automaticamente para a inserção do pensamento aristotélico na Idade Média. O impacto das teorias políticas de Aristóteles revolucionou o pensamento sobre as concepções básicas da sociedade e seu governo. Houve três fases de assimilação dessa ideologia: uma primeira de hostilidade, uma segunda de adaptação de suas doutrinas à estrutura cristã e uma terceira de abandono progressivo dos elementos cristãos. A doutrina aristotélica tinha o Estado como uma comunidade suprema de cidadãos, formado pelas leis da natureza, em que estas fossem inerentes ao homem enquanto tal. (ULLMANN, 1997, p. 160). O sujeito nasceu para viver em uma comunidade auto-suficiente, independente e autônoma, sem a qual não conseguiria viver ou alcançar sua perfeição.

A influência de Aristóteles, de cujas obras se tiveram acesso no começo do século XIII, tropeçou em vários obstáculos. Um deles é o fato de essas somente serem conhecidas através de traduções árabes e hebraicas e não em seu texto original, tanto que Alain de Libera (1999, p. 108) chega a afirmar que foi Avicena, não Aristóteles, que iniciou o Ocidente na filosofia. É por meio de Avicena que o pensamento muçulmano sobre a Idade Média latina adquire seu primeiro e verdadeiro contorno, iniciando o Ocidente na razão e na racionalidade religiosa. Os pressupostos básicos do aristotelismo pareciam por completo inaceitáveis, como por exemplo, a concepção da continuidade da evolução e sua visão de causalidade que excluíam a idéia de um começo determinado do mundo e, em conseqüência, o princípio original da criação divina do universo, assim como a possibilidade de obrar milagres e a diferente visão sobre a imortalidade em comparação com a concepção cristã. As leis da natureza determinavam a capacidade de pensar e raciocinar, o homem determinava a verdade e o erro examinando e compreendendo o que a natureza exigia. (ULLMANN, 1997, p. 161).

Neste compasso, Gregório IX proíbe o estudo de Aristóteles em Paris, sendo estas obras analisadas e "purificadas" pelos frades dominicanos Guilherme de Moerbecke, Alberto Magno e 
Tomás de Aquino. De acordo com essa discussão, Libera $(1999$, p. 110) professa que foi no mundo muçulmano que se efetuou o primeiro confronto entre o monoteísmo e o helenismo - entre a razão e a fé. Logo, o problema intelectual do Ocidente não ocorreu devido ao encontro da fé cristã com a razão greco-árabe, mas sim da interiorização das contradições do racionalismo religioso árabe. No próprio Islã, o "averroísmo" é uma estrutura de pensamento que exprime um conflito interno à racionalidade. Com isto, no Ocidente principia a adaptação dos ideais do antigo filósofo à cosmologia cristã, encarada como uma tarefa de urgência. Tomás de Aquino cria uma síntese a partir de elementos díspares e irreconciliáveis em que o pensamento aristotélico parecia despojado de elementos que pudessem afetar o ponto de vista teocêntrico. Pelo pensamento tomista, o que distinguia a criatura racional da irracional era a capacidade daquela para raciocinar, ou seja, para perceber a lei eterna de Deus. Então, o homem, por meio da lei natural participava da lei eterna de Deus. (ULLMANN, 1997, p. 166 e p. 172).

Tomás sustentava que era o instinto natural do homem que originava o Estado - a sociedade humana organizada. Com o Estado se abria um abismo entre a comunidade política e a Igreja, já que esta havia sido instituída pela divindade. Quanto à teoria jurídica, a lei positiva humana dependia de sua correspondência com a lei natural, afinal, se o Estado derivava da natureza, as leis deste também deviam. A lei divina não diferia da lei positiva sempre que esta se baseasse na razão natural. Dessa forma, toda lei era norma e medida das ações humanas e a fonte última de toda norma era a lei eterna de Deus - estando este viés intimamente ligado ao cristianismo. Apesar da natureza e a graça aparentemente parecerem distantes, no sistema tomista estes conceitos ganham no lugar do contraste uma hierarquia de diferentes ordens. O natural e o supranatural tornam-se complementares e, por conseqüência, os formadores da dupla ordem das coisas. O elemento conceitual que permitia essa percepção equivalia à noção de que a natureza tem Deus como autor e regente do mundo.

Este dualismo de um corpo natural (comunidade humana) e um corpo supranatural (Ecclesia - comunidade de cristãos) supõe uma mudança drástica de pensamento para os contemporâneos de Tomás de Aquino, visto o sistema cósmico do Estado ser aplicável a sociedades não-cristãs. 0 homem poderia ser visto sobre dois ângulos: o ângulo natural do homem e o ângulo supranatural do crente cristão. Para Ullmann é evidente que o sistema tomista era frágil, requeria um tratamento muito delicado e não se via livre de defeitos, porém quando surgiram estas idéias o terreno estava preparado para isso, causando um ataque em grande escala contra as bases da concepção tradicional de sociedade e governo. De maneira geral, Tomás de Aquino defendeu que - o natural e o supranatural - encontravam-se em harmonia e que sob uma autoridade única não haveria necessidade de separação entre as duas esferas de poder na existência humana. A Igreja e a comunidade estariam unidas na figura do Sumo Pontífice. (ULLMANN, 1997, p. 175). Esse postulado de consonância entre os dois poderes foi fundamental para a elaboração do pensamento encontrado no Monarchia: partindo também de uma concepção dualista, Dante defendia a independência mútua do Papa e Imperador, ao invés de uma subordinação do gládio material, visto que ambos os poderes derivavam diretamente de Deus. 
2. Um mundo sem nobreza para Dante é impensável, pois é no homem nobre que se realiza a ordem total das coisas, sua ligação completa. O ințelectual não é um simples intermediário, um funcionário da deidade, mas é antes um homem "divino" que pela filosofia corresponde ao outro Deus encarnado. A invenção do intelectual por Dante está além da nobreza de linhagem ou da nobreza de ofício, é uma nobreza astral, fruto natural da ordem na natureza (LIBERA, 1999, p. 277).

Dante Alighieri, tanto no Convivio (1304) como no De Monarchia (1312-3), defende o exercício intelectual como um valor que o sujeito deve possuir para exercer uma das duas beatitudes que possui: a beatitude terrestre e a beatitude celeste. No Convivio encontramos a delineação de uma existência perfeita e "nobre", deixando claro que a cultura do espírito se reserva a uma elite, corifeu da comunidade humana, atribuindo um grande valor à razão, sempre se preocupando através de quais métodos reconquistar/fundar a verdadeira "nobreza". A vida ativa, a ação do indivíduo na sociedade e do político na cidade, são fatores que também contém grande importância nesta obra, enquanto no Monarchia preocupa-se mais em separar em dois caminhos precisos o princípio do duplo fim (TORRES, 2006, p. 7). As duas beatitudes apresentadas por Dante são percebidas em alguns trechos do Convivio:

De onde, como aquela que é aqui a humana natureza não tem uma só beatitude, mas duas, qual a da vida social e a da vida contemplativa, irracional seria que aceitássemos terem aqueles (falando dos anjos) a beatitude da vida activa, isto é, social, no governo do mundo e não terem a da contemplativa, mais excelente e mais divina (DANTE ALIGHIERI, 1992, Conv., II, IV).

Em verdade o uso do nosso espírito é duplo, isto é, prático e especulativo (prático significa operativo). O dom prático consiste em obrar por nós virtuosamente, isto é, honestamente, com prudência, com temperança, com fortaleza e com justiça (ou seja, as quatro virtudes morais); o do especulativo não é obrar por nós, mas considerar as obras de Deus e da natureza (DANTE ALIGHIERI, 1992, Conv. IV, XXII).

E assim aparece que a nossa beatitude (esta felicidade de quem se fala) primeiro a podemos encontrar, imperfeita, na vida activa, isto é, nas operações das virtudes morais, e depois, perfeita, nas operações intelectuais" (DANTE ALIGHIERI, 1992, Conv., IV, XXII).

Dante Alighieri, mais que qualquer outro, foi quem defendeu a "nobreza" intelectual. No Convivio a teologia de Aristóteles e a astrologia se fundiram num manifesto filosófico escrito em volgare toscano, pretendendo se dirigir, não aos Doutores das Universidades, mas aos homens da nobreza e do governo da cidade, crente que essa categoria superior e restrita possuía os germens da verdadeira nobreza. Nesta obra, Dante expõe a tese central do "aristocratismo intelectual", especificando a verdadeira figura do pensador medieval, o coroamento natural das virtudes seria um estado de felicidade particular: a felicidade mental - a contemplação filosófica. No entanto, para que isto ocorresse era necessário possuir a nobiltade, que não pode ser alcançada a não ser por intermédio de Deus, "o olhar de Dante não é o de um sociólogo, é o de um filósofo da natureza. A teoria de nobiltade se inscreve numa visão do cosmo: a nobreza recai sobre certos homens virtuosos". (LIBERA, 
1999, p. 253). E ao fazer apologia à nobreza (nobiltade), defende uma nova visão da existência, de um novo ideal que transpõe o de vida filosófica que durante os séculos XIII e XIV se apoderaram da Universidade de Paris. O emprego da língua vulgar fez passar para a sociedade o modelo de vida que os mestres em artes se haviam dado, universalizando o ideal universitário, representando o "intelectual" de fora dessas instituições.

A interpretação da existência humana é feita através de uma dupla ordem, ao mesmo tempo distinta e convergente: a da natureza e a da graça. No livro terceiro do Monarchia, o pensador florentino defende que o homem, e somente ele, detém o meio das coisas corruptíveis e incorruptíveis, assim como se considera o sujeito segundo uma e outra parte essencial: a alma e o corpo. E como toda natureza está ordenada para um fim último, resulta que o homem exista para um duplo fim. Dentre estes dois, a beatitude desta vida consiste no exercício da própria virtude, que é representada pelo paraíso terrestre e a beatitude da vida eterna, cuja essência consiste na fruição da presença divina (DANTE ALIGHIERI, 1973, Mon., III, XVI).

Para Dante toda vida humana está subordinada à realização da sabedoria teorética, ou seja, toda ciência contemplativa ou fundada sobre a contemplação da verdade, que antecipa e prepara para o alcance da beatitude. De acordo com Libera, há uma lei do dom: "Convém que as coisas estejam dispostas a seus agentes, e a receber seus atos", um axioma aristotélico. Assim, a nobreza intelectual é colocada no limite que separa a Filosofia da Teologia. Dante comenta que embora a beatitude eterna seja superior à terrestre, uma é necessária para alcançar a outra. Apresenta também a contemplação filosófica como o objetivo de toda organização humana, sendo esta o último fundamento da idéia monárquica. (LIBERA, 1999, p. 257). A monarquia temporal defendida por Dante Alighieri resgata a doutrina aristotélica de que toda essência existe em vista de sua operação. Nenhuma essência criada pode ser a intenção última do Criador, buscando por este expediente um fim próprio para o gênero humano em sua totalidade: o conhecer pelo intelecto.

Acredita que a nobreza seja individual e intransmissível, a nobreza coletiva não passaria de uma idéia abstrata, não defende o mérito individual, nem reivindica uma dignidade para um novo grupo social. O grupo dos intelectuais será nobre se cada um dos membros que a compuserem for nobre. Então todo o problema é saber de que maneira a nobreza incide nos indivíduos, por que em uns e não em outros; se nem a origem ou a função social podem enobrecer o homem. Assim, a cosmologia de Aristóteles e de seus comentadores e a teologia pseudo-aristotélica do Livro das causas é o que envolve Dante e é a esse mundo que se aplicam a teoria e a prática astrológica. Segundo Libera, o pensador florentino professa o caráter divino e extrínseco daquilo que faz a humanidade mesma do homem - seu intelecto. Ao fazer da alma do homem nobre algo que desce a ele, define um tipo de homem cósmico e, a partir de premissas biológico-astrológicas, estabelece uma genealogia do enobrecimento.

Ao afirmar que a alma nobre desce à alma humana para nela exercer a totalidade de seus poderes ou operações, Dante vai, portanto além de todos os limites permitidos: o homem nobre torna-se verdadeiramente o lugar-tenente terrestre do Uno-Todo. Ele não apenas 
está inscrito na ordem do universo, é essa ordem mesma que se inscreve nele. Ele é o nexus mundi descido a terra, ou, segundo uma outra metáfora, o horizonte do céu e da terra. "A influência" não mais se exerce sobre ele, mas dentro dele, através dele. (LIBERA, 1999, p. 271).

A partir deste excerto e ao inserir esta reflexão filosófica ao contexto histórico da produção da Monarchia, percebemos que esta alma nobre é encarnada, principalmente, pelo Imperador Universal, o chefe necessário para o estabelecimento da paz nas repúblicas italianas e que possui domínio sobre todas as coisas que vivem e são medidas pelo tempo. A teorização astrológica dantesca para a caracterização do homem "nobre" encontrada no Convivio é elaborada não somente para apresentar e justificar um grupo de indivíduos que possui a "semente divina", mas também fortalecer os alicerces para seu posterior tratado político De Monarchia. Nesta obra, Dante ao professar a respeito da necessidade da Monarquia temporal, recorre de modo intermitente à legitimação do poder Imperial concedida por Deus ou a predestinação divina do Império, visto a discussão tornar-se mais intensa nos momentos em que urge estabelecer a independência do poder temporal em relação ao espiritual, ou seja, esclarecer a vinculação direta do Imperador com Deus. Portanto, é perceptível a relação que se estabelece entre a divindade e o Monarca, concebendo, antes uma teoria de "nobreza" intelectual destinada aos poucos homens escolhidos por Deus, do que um argumento somente para fundamentar a distinção de poderes.

\section{Fontes:}

DANTE ALIGHIERI. Monarquia. Trad. Carlos Eduardo de Soveral. In: Seleção de textos: (Tomás de Aquino, Dante Alighieri, John Duns Scot, Willian of Ockham). Os Pensadores. Sãó Paulo: Abril Cultural, 1973.

Convívio. Trad. Carlos Eduardo de Soveral. Lisboa: Guimarães Editores, 1992.

\section{Bibliografia:}

BARBOSA, João Morais; SOUZA, José Antônio de C. R. de. O Reino de Deus e o Reino dos Homens. As relações entre os poderes espiritual e temporal na Baixa Idade Média (da Reforma Gregoriana a João Quidort). Porto Alegre: EDIPUCRS, 1997.

DORÉ, Andréa Carla. "Dante Alighieri e as relações internacionais". In: Contexto Internacional, vol. 19, n. 1. Jan/Jun 1997, p. 97-130.

FERNANDES, Fátima Regina. "O conceito de Império no pensamento político tardo-medieval". In: Facetas do Império na História: conceitos e métodos. São Paulo: Hucitec, 2008. 
FRANCO JR., Hilário. Dante Alighieri: o poeta do absoluto. São Paulo: Ateliê Editorial, 2000.

GILSON, Etiénne. Evolução da Cidade de Deus. Trad. João Camilo de Oliveira Torres. São Paulo: Herder, 1965.

LIBERA, Alain de. Pensar na Idade Média. Trad. Paulo Neves. São Paulo: 34, 1999.

MIETHKE, Jürgen. Las ideas políticas de La Edad Media. Trad. Francisco Bertelloni. Buenos Aires: Biblos, 1993.

TORRES, Moisés Romanazzi.. “A perspectiva "pedagógica” de Dante Alighieri no acesso à verdadeira nobreza e à beatitude terrestre". Mirabilia, v. 6, p. 9, 2006. Disponivel em: http://www.revistamirabilia.com/ Numeros/Num6/art9.html.

ULLMANN, Walter. Historia del pensamiento político em la edad media. Barcelona: Ariel, 1997. 